\title{
The Characteristics of Organic Compounds in Landfill Leachate Biologically Treated under Different Technological Conditions
}

\author{
Justyna Koc-Jurczyk ${ }^{1 *}$, Łukasz Jurczyk ${ }^{1}$ \\ ${ }^{1}$ University of Rzeszow, College of Natural Sciences, Institute of Agricultural Sciences, Land Management and \\ Environmental Protection, ul. Cwiklinskiej 1a, 35-601 Rzeszow, Poland \\ * Corresponding author's e-mail: jjurczyk@ur.edu.pl
}

\begin{abstract}
In this work, the semi-synthetic wastewater made of the leachate derived from non-hazardous municipal waste landfill in Kozodrza (south-eastern Poland) and supplemented by ammonium, was treated in hybrid SBRs to assess the removal efficiency of organic compounds, including humic substances and dissolved fractions, depending on the technological conditions. The technological layout variants concerned both the volumetric proportions of aerated and anoxic zones $(0.33$ and 0.66$)$ as well as the $\mathrm{N} / \mathrm{C}$ ratio $(0.1$ and 0.2$)$. It was found that the efficiency of organic compounds removal (expressed as $\mathrm{COD}, \mathrm{BOD}_{5}$ and $\mathrm{TOC}$ ) was influenced by the geometry of oxygen supply; in the SBRs operating with 0.33 ratio, it was significantly higher compared to that with 0.75 ratio. The analysis also revealed that the N/C ratio set at 0.1 resulted in higher treatment efficiency than that obtained for 0.2 . The composition of dissolved organic fractions in outflows was also related both with the SBRs geometry and the N/C ratio. It was found that proportions of TOC and humic substances were significantly lower in the SBRs operating with aeration geometry of 0.33 , compared to the ones working with 0.66 . Moreover, the N/C ratio of 0.1 led to a higher content of dissolved humic substances and COD in outflows.
\end{abstract}

Keywords: landfill leachate, hybrid SBR, dissolved organic matter, organic fractions

\section{INTRODUCTION}

In Poland, one of the most popular methods utilized for municipal landfill leachate (LL) disposal is the co-treatment with domestic wastewater, or for lack of other options, continuous recirculation back to the top of the waste pile. The implementation of so-called Regional Municipal Waste Processing Installations (pol. RIPOK), limits the total number of landfills; thus, higher volumes of waste is concentrated in a single localizations. This, in turn, increases the technical requirements for the infrastructure including the interest for technologies dedicated strictly to this type of wastewater (LL). However, specific conditions in which LL is created and the resulting composition lead to such technological problems as: a large loads of particular pollutants (e.g. ammonium nitrogen), complex composition including compounds toxic not only for the environmental components, but also the biological elements of treatment systems (e.g. activated sludge); moreover, the unfavorable ratio of the bio-available forms of carbon and large seasonal as well as long-term quantitative and qualitative changes (Miao et al. 2019).

The above-mentioned problems draw the attention of the environmental engineers on the physio-chemical methods rather than other alternative solutions. However, the biological treatment is still one of the most widely used methods, mainly due to the low operational costs and simplicity. The implementation of a sequencing batch reactor (SBR) in landfill installations, due to its potential to maintain high biomass concentration and long age of sludge, is currently quite a popular approach, especially in multi-stage treatment systems. Thus, the attempts to design a high-performance SBR based on fluidized beds or suspended biomass reactors are being made. The studies on 
improving the efficiency of nitrification were also conducted using combined methods - activated sludge together with biological membrane on moving or stationary biomass carriers (Masłoń, Tomaszek, 2015).

Numerous studies have been done on different growth media (carriers) added to MBRs as submerged membrane, including: polyurethane cubes, polystyrene beads, polyethylene molds (Kaldnes), activated carbon (granular and powdered), zeolite, blasted clay granules or sponge (Huang et al., 2008; Khan et al., 2011). The sponge structured materials could acts as a moving carrier for the biologically active biomass and helps to retain microorganisms by incorporating a hybrid growth system including both their attached and suspended growth environments. These materials have been considered as feasible for the technical scale applications due to high porosity owing to their well developed specific surface area for microbial immobilization, also good mechanical and hydrodynamical properties useful for membrane fouling control, and low cost of manufacturing (Chu, Wang, 2011). Lim et al. (2012) reported that biomass plays a crucial role in the ammonia nitrogen oxidation in hybrid systems suspended, while the biomass inhabiting the interior of the polyurethane foam is utilized as a carbon source in the process of denitrification. The addition of such carrier in volume of 10 to $20 \%$ of the reactor maintains the biofilm growth for effective nutrients removal and provides membrane scouring for fouling reduction (Ngo et al., 2008; Guo et al., 2010).

Currently, a lot of scientific information is available on the biological removal of organic substances expressed as e.g. chemical (COD) or biological oxygen demand $\left(\mathrm{BOD}_{5}\right)$, total organic carbon (TOC) and humic substances (HS). However, this mainly applies to the so-called macroscale compounds, whilst the micro-scale organic is just as important from a technological point of view (Campagna et al., 2013). Determination of the dissolved organic matter (DOM) concentration and quality in raw and treated LL allow designing the optimal and efficient layout of biological system. Ozkaya et al. (2005) found that the biodegradable fraction in LL is the most effectively removed during biological process, while non-biodegradable fraction passes through the system almost unchanged. It is important in the context of a widely known fact that the content of non-biodegradable fraction in LL rises rapidly as the age of the landfill increases.

The aim of the study was to assess the removal efficiency of organic compounds, including humic substances and dissolved fractions, depending of the technological variants covering volumetric proportions of oxygenated and anoxic zones and the $\mathrm{N} / \mathrm{C}$ ratio.

\section{MATERIALS AND METHODS}

The LL used in this study was sampled from a municipal, non-hazardous waste landfill operated since 1990, which currently has a status of regional installation for the western region of Podkarpackie Province (south-eastern Poland) and collects average mass of $218 \mathrm{Mg}$ /day (maximum up to $360 \mathrm{Mg} / \mathrm{d}$ ) and $55808 \mathrm{Mg} / \mathrm{a}$ (up to $92,160 \mathrm{Mg} / \mathrm{a}$ ), while the mass intended to recovery reaches $4,220 \mathrm{Mg} / \mathrm{a}$

At present, waste has been gathered in 11 quarters that are already closed, covered with ground layer and undergoing the process of reclamation, and in one active quarter - all the area covers over 18 ha, from which LL is drained to reservoirs, and then directed to further biological and physical processing. According to the national legislation and Integrated Permit by the Marshal of the province (OS.I.7222.45.6.2015.RD), LL is classified as industrial wastewater and could be generated in an amount up to $30.2 \mathrm{~m}^{3} / \mathrm{d}$ (Figure 1).

For this study four SBRs have been designed, differing in the ratio of aerated volume to mixed volume: 0.33 in SBR1 and 2, and 0.66 in SBR 3 and 4 . The layout was complemented by differentiation of N/C ratio in the inflows; 0.1 in SBR1 and 3 , and 0.2 in the remaining two.

The reactors were filled with PU foam with a porosity of 15 ppi (Figure 2), to occupy $10 \%$ of geometric active volume of each phase. The characteristic of the biomass carriers is shown in Table 1.

All the measurements and calculations were performed according to methodology described in (Koc-Jurczyk and Jurczyk 2017). The hydraulic retention time in SBR was set at $3 \mathrm{~d}$, and the operating cycle lasted for 24 hours, including 1.45 hours of sedimentation, 10 minutes of decantation and 5 minutes of refilling. During the treatment, constant temperature of $25^{\circ} \mathrm{C} \pm 0.2$ was maintained. The concentration of organic 


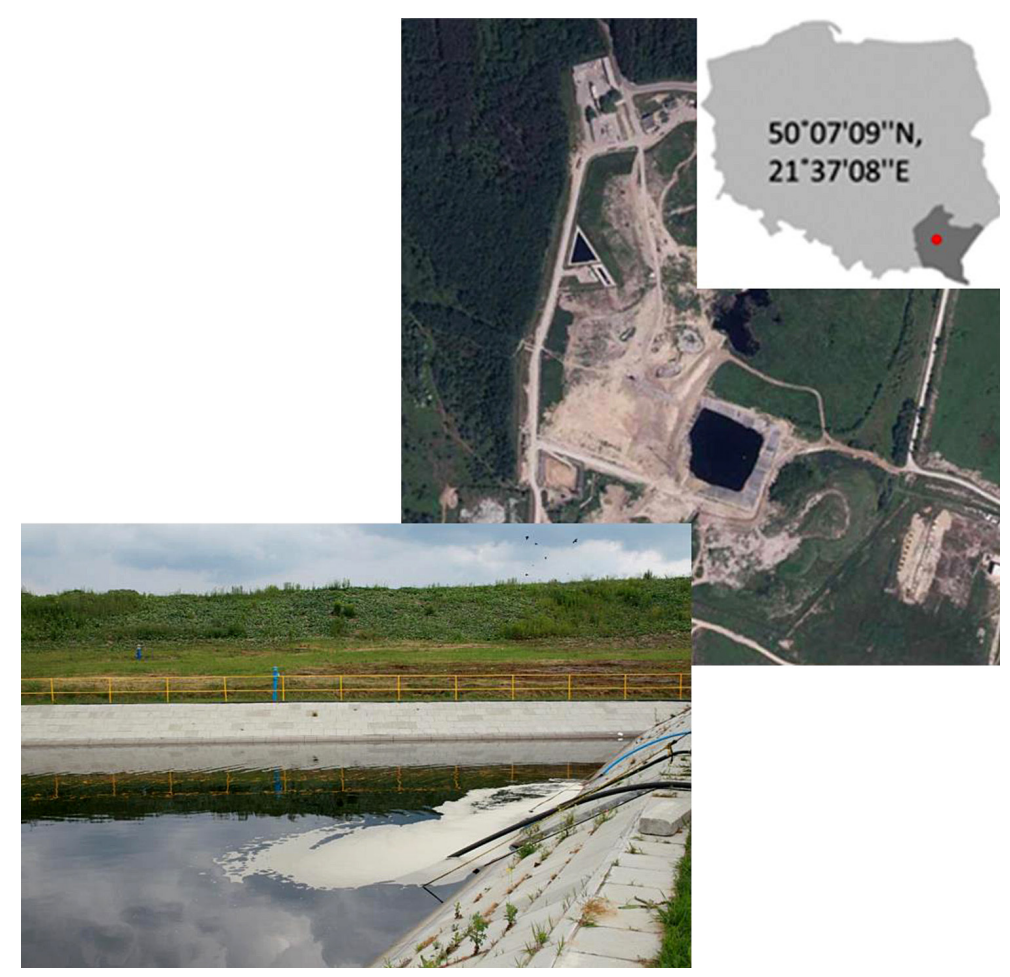

Figure 1. The localization of municipal waste landfill (southeastern Poland), a satellite photo of the landfill area, and retention tank gathering LL from active area

compounds expressed as $\mathrm{COD}, \mathrm{BOD}_{5}$, TOC and humic substances was determined in the raw and treated leachate according to the APHA methodology. The concentration of particular dissolved forms of organic matter (DOM) was also determined after filtering through a membrane with a $0.45 \mu \mathrm{m}$ pore diameter.

Raw LL was characterized by the concentration of organic compounds at the level of $15,600 \mathrm{mg} / \mathrm{L}$ (COD), $565 \mathrm{mg} / \mathrm{L}\left(\mathrm{BOD}_{5}\right)$ and $642 \mathrm{mg} / \mathrm{L}$ (TOC), whilst the concentration of humic substances amounted to $202 \mathrm{mg} / \mathrm{L}$. In order to equilibrate the ratio of nitrogen to organic compounds, the concentration of ammonium was slightly adjusted from the encountered level to
$1560 \mathrm{mg} / \mathrm{L}(\mathrm{N} / \mathrm{C}=0.1)$ or increased to $3200 \mathrm{mg} / \mathrm{L}$ $(0.2)$ by adding a water solution of $\mathrm{NH}_{4}\left(\mathrm{SO}_{4}\right)_{2}$.

The statistical analyses of the obtained results were carried out by the Mann-Whitney nonparametric test (assuming a level of significance of $\alpha=0.05$ ), also the Pearson's correlation coefficients between specific indicators were analyzed (Statistica 13).

\section{RESULTS AND DISCUSSION}

While analyzing the obtained results, it was found that the highest efficiency of organic substances removal (COD, $\mathrm{BOD}_{5}$ and $\left.\mathrm{TOC}\right)$, was

Table 1. Parameters of PU foam cuboids used in the experiment as the biomass carriers

\begin{tabular}{|c|c|c|}
\hline Parameters & Foam A & Foam B \\
\hline Size $[\mathrm{cm}]$ and porosity [ppi] & $2,5 \times 2,5 \times 8 / 15$ & $2,5 \times 2,5 \times 2,7 / 15$ \\
\hline Foam cuboids area $\left[\mathrm{cm}^{2}\right]$ and volume $\left[\mathrm{cm}^{3}\right]$ & 50 & 16.87 \\
\hline Measured mean strut length [mm] & \multicolumn{2}{|c|}{$1.954( \pm 0.398)$} \\
\hline Pore mean openness coefficient $\left(k_{A}\right)$ & \multicolumn{2}{|c|}{0.2873} \\
\hline Estimated single cell volume $\left[\mathrm{cm}^{3}\right]$ & \multicolumn{2}{|c|}{0.0756} \\
\hline Est. single cell surface area $\left[\mathrm{cm}^{2}\right]$ & \multicolumn{2}{|c|}{0.2728} \\
\hline Est. specific surface area $\left[\mathrm{cm}^{2} / \mathrm{cm}^{3}\right]$ & \multicolumn{2}{|c|}{5.867} \\
\hline Est. total area of biomass carriers $\left[\mathrm{cm}^{2}\right]$ & 2867.38 & 980.936 \\
\hline Sum of biomass carrier area $\left[\mathrm{cm}^{2}\right]$ & \multicolumn{2}{|c|}{3848} \\
\hline Hydraulic load of carrier surface $Q_{h}\left[\mathrm{~cm}^{3} / \mathrm{cm}^{2} \mathrm{~h}\right]$ & \multicolumn{2}{|c|}{0.08} \\
\hline
\end{tabular}




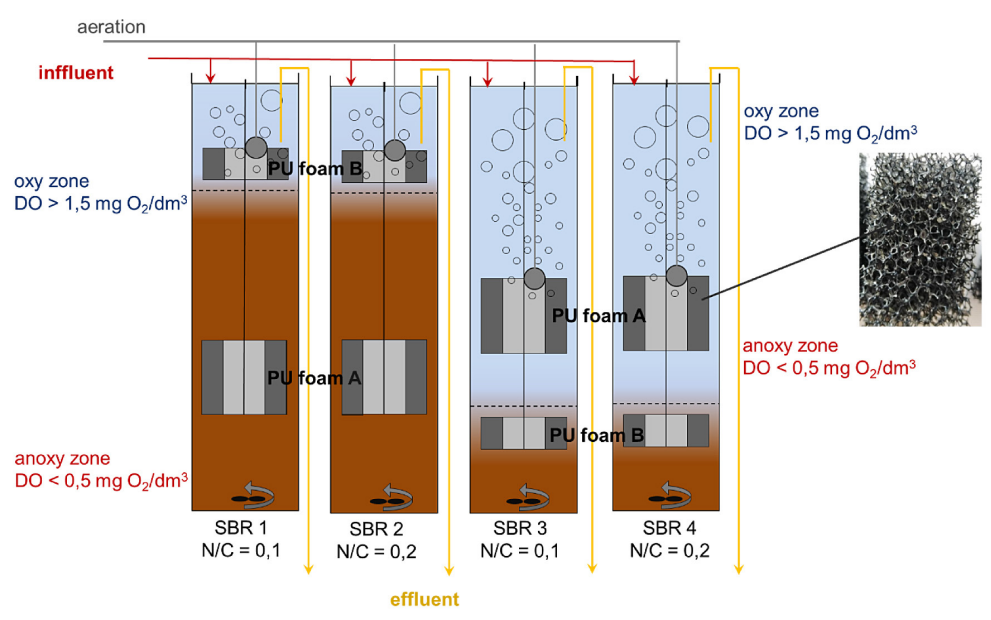

Figure 2. Scheme of the SBRs layout

found in SBR 1 operating with oxygen supply geometry 0.33 and $\mathrm{N} / \mathrm{C}$ ratio 0.1 (Figure 3 ).

The higher consumption rate of organic matter in the reactors having a proportion of aerated volume of 0.33 would be, simply speaking, an effect of higher number of microorganisms inhabiting larger total area of foam carrier immersed in anoxic volume which consumed the available carbon to sustain the process of simultaneous nitrification and denitrification (SND). This was confirmed by research of Lim et al. (2011), who reported that the carbon in the denitrification process could be obtained from the storage inside the deep layer of PU foam. The N/C ratio also had an impact on the efficiency of the organic matter removal. Regardless of the volumetric ratio of actively oxygenated phase, both reactors supplied with the inflows containing $1560 \mathrm{mg} \mathrm{N} / \mathrm{L}$ showed a higher efficiency in organic matter removal than the other reactors, where the $\mathrm{N} / \mathrm{C}$ ratio in the inflowing LL was 0.2.
However, comparing the values of the particular organic pollution indicators in the outflows it was stated that, in the case of COD, statistically significant differences were found only between the reactors that were treating LL, which differ in the N/C ratio (between SBR 1 and 2 and between 3 and 4 ).

On the other hand, different aeration geometry layouts did not affect the efficiency of treatment significantly. Additionally, the statistical analysis, neither in the case of N/C ratio nor oxygen supply geometry, showed significant differences between the concentrations of organic compounds expressed as $\mathrm{COD}, \mathrm{BOD}_{5}$ and TOC in the outflows from all the reactors (Figure 4).

The analysis of the relations between particular pollution indicators after the biological treatment showed correlation between the COD values as well as both $\mathrm{BOD}_{5}$ and TOC in the outflows from the SBRs operated in the aeration geometry of 0.33 , whereas the geometry of 0.66

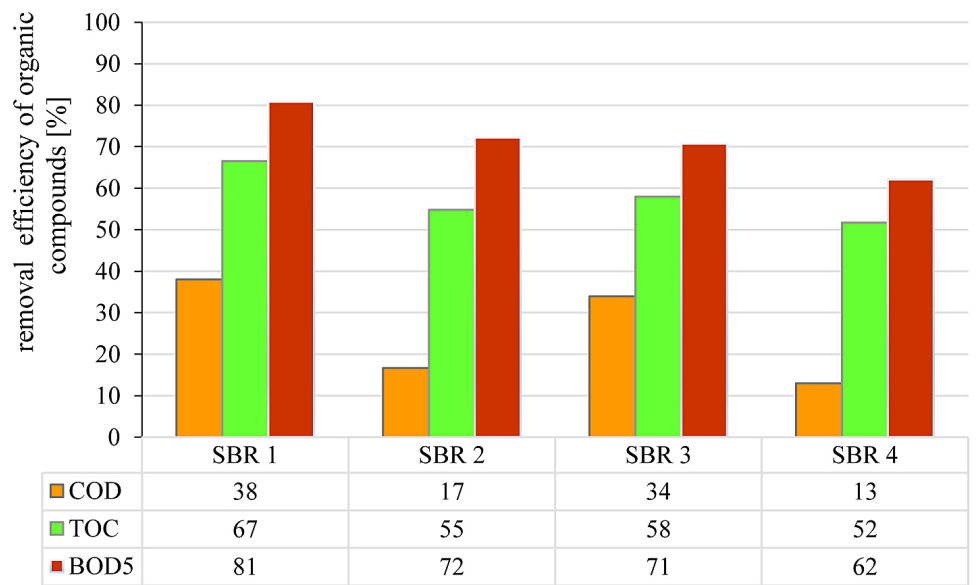

Figure 3. Removal efficiency of organic compounds (COD, $\mathrm{BOD}_{5}$ and $\left.\mathrm{TOC}\right)$ in different configurations of oxygen and nitrogen supply to SBR 
a)
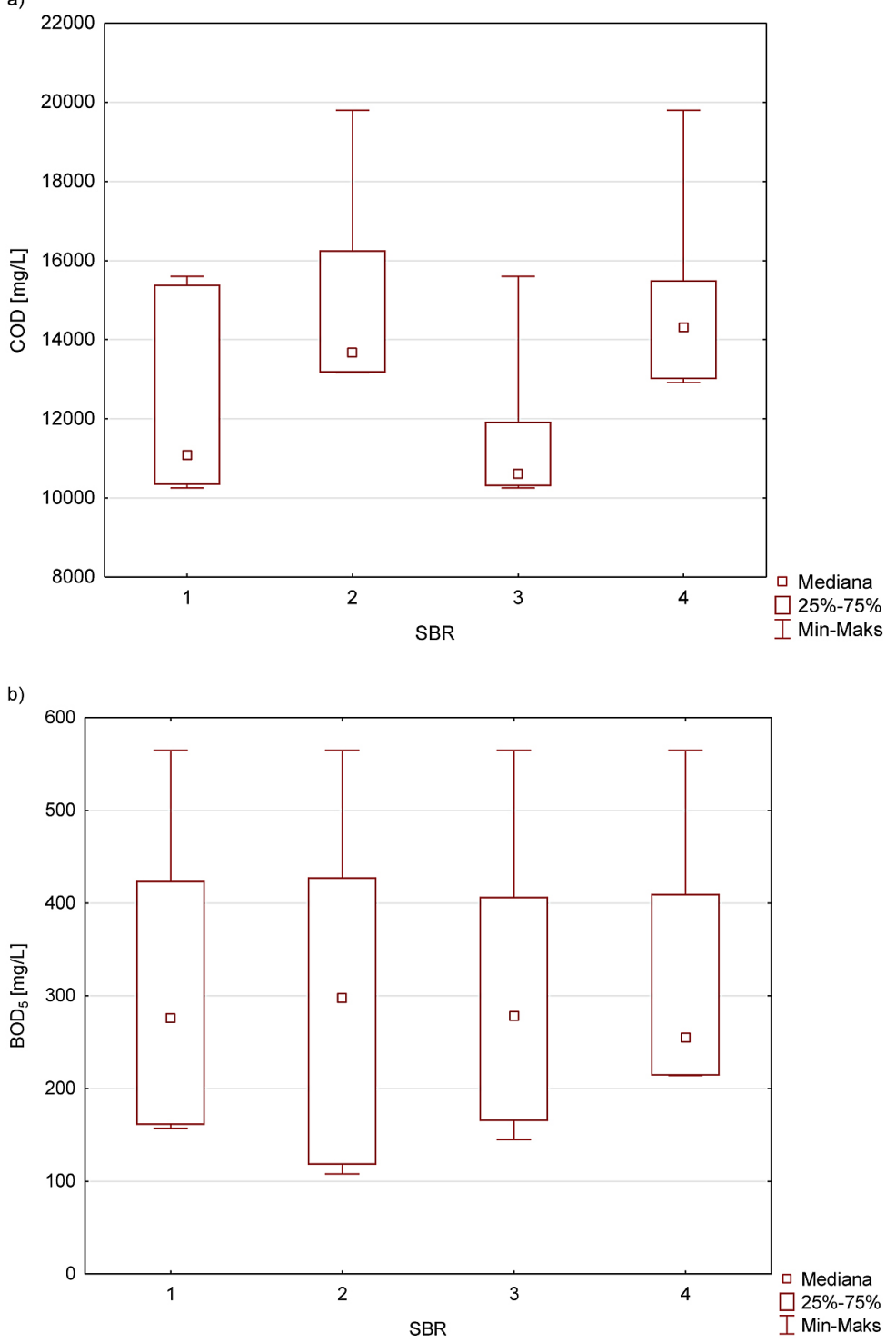

c)

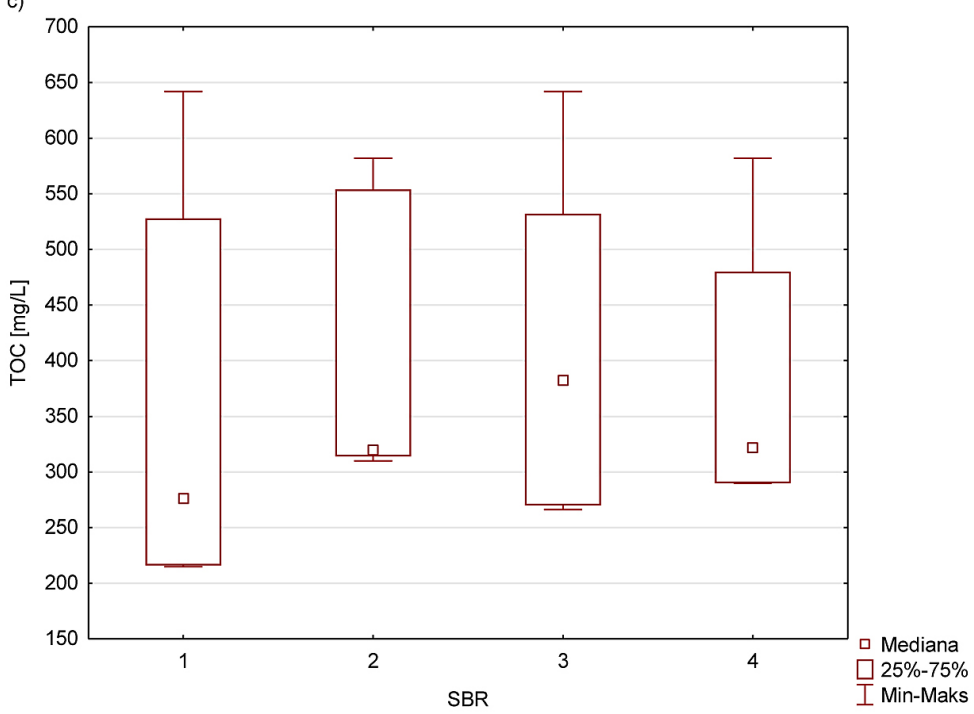

Figure 4. Concentration of organic compounds expressed as $\mathrm{COD}(\mathrm{a}), \mathrm{BOD}_{5}(\mathrm{~b})$ and TOC (c) in the outflows from hybrid SBRs 
has also caused the correlation between COD and concentration of HS. Regardless of the technological variant used, the $\mathrm{BOD}_{5}$ value was always correlated with TOC (Figure 5).

In this work, the concentrations of organic compounds in the dissolved form (DOM) were compared between the raw and treated LL, as well. In raw leachate, the dissolved fraction of COD formed nearly $88 \%$, TOC $-52 \%$, and in the case of HS, even more than $98 \%$.

As it was assumed, in all of the afore-mentioned pollution indicators, the percentage of dissolved fraction decreased after the biological treatment. When it comes to COD and HS, better effects of biological removal occurred in the SBRs that were fed with $L L$ of $\mathrm{N} / \mathrm{C}$ ratio 0.2 , regardless of the oxygen supply geometry. However, in the case of TOC, higher efficiencies were revealed after treatment with $\mathrm{N} / \mathrm{C}=0.1$ ratio (Figure 6).

Considering the fact that generally higher removal efficiency was obtained in $\mathrm{N} / \mathrm{C}=0.1$, and taking into account that from the technical point of view also some mineral compounds (e.g. chlorides) could affects on COD assay, it can be stated that TOC is the suitable indicator for determination of the dissolved organic substances uptake rate by the microbial community of activated sludge inhabiting the LL treatment systems. This is confirmed by the efficiency of TOC removal, which was quite higher in those reactors, where the concentrations of the soluble fraction in the outflows was lower, both by analyzing the influence of the N/C ratio and the oxy / anoxy phase in the SBR geometry. The highest reduction of dissolved organic fraction was observed in the case of HS. This could means that during the biological treatment of LL, humic substances with particles below $45 \mu \mathrm{m}$ are preferred by the activated sludge as a carbon source. According to He et al. (2006), DOM are often described as organic molecules of different molecular weights (MW) and structures that could pass through $0.45 \mu \mathrm{m}$ filtration membranes, including low MW substances like amino acids, carbohydrates, organic acids, and some high MW substances like humic substances.

A statistical analysis (at the confidence interval 95\%) of the obtained results showed that the correlation between the concentration of organic pollution indicator and concentration of its dissolved fraction was significant in the case of TOC and HS, but only in the reactors operating with the oxygen supply geometry of 0.66 (SBR 3 and 4) (Figure 7), while in the outflows from SBR 1 and 2 , such relations were not proven.
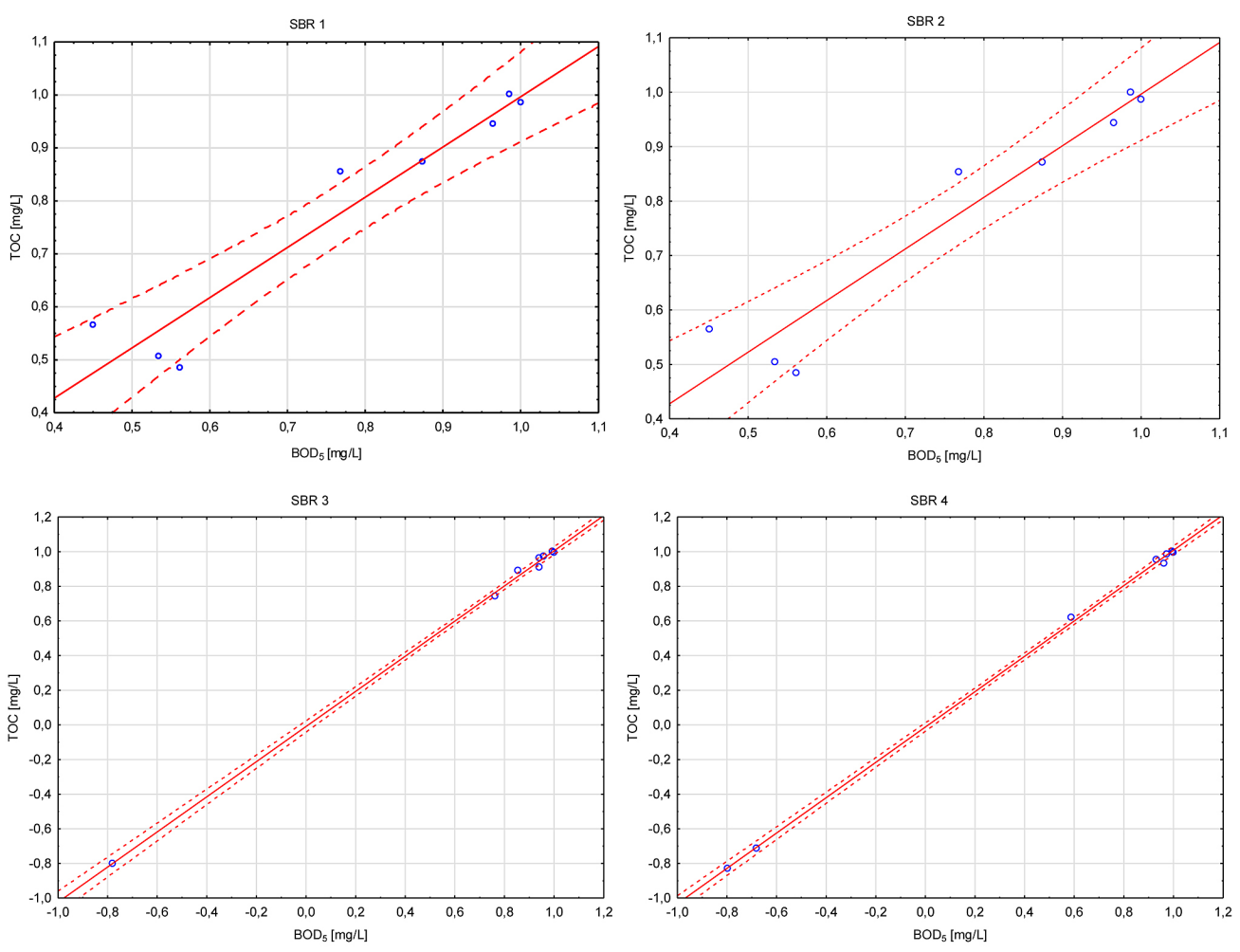

Figure 5. Correlation between $\mathrm{BOD}_{5}$ and TOC in in the outflows from hybrid SBRs (at the confidence interval 95\%) 


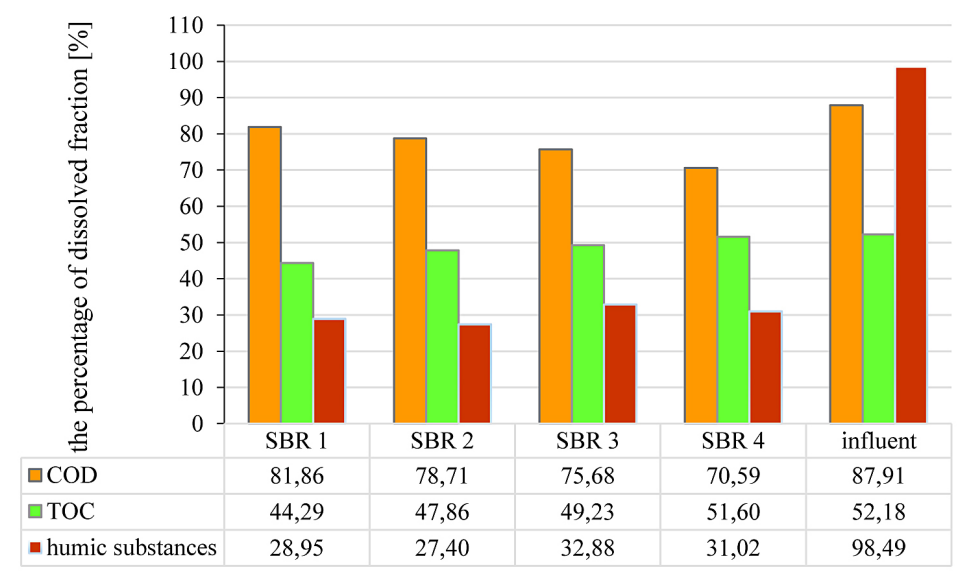

Figure 6. The percentage of dissolved fraction (COD, TOC and humic substances) in different configurations of oxygen and nitrogen supply to SBR
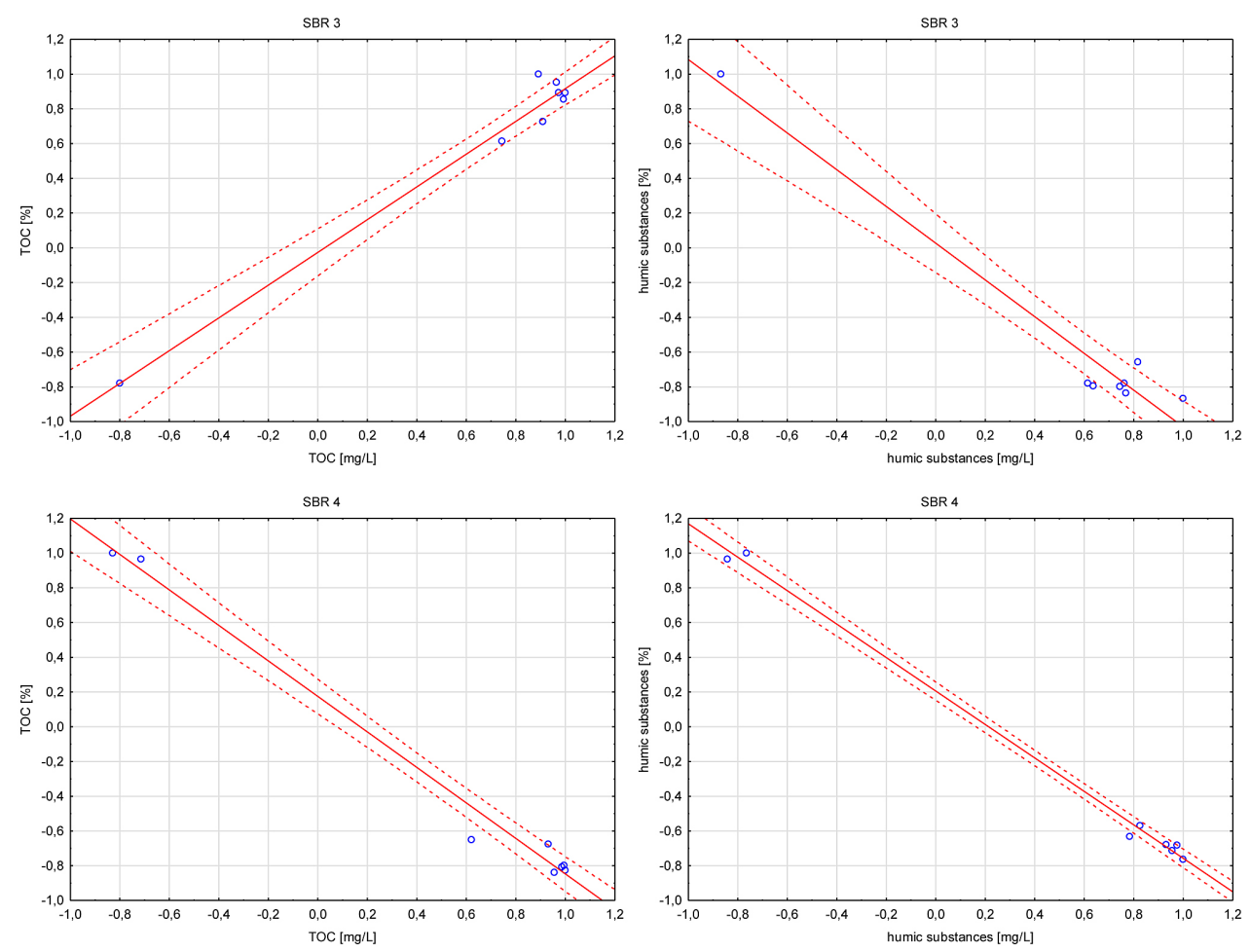

Figure 7. Correlation between the concentration of organic pollution indicator and concentration of its dissolved fraction (TOC and humic substances) in in the outflows from hybrid SBR 3 and SBR 4 (at the confidence interval 95\%)

Berthe et al. (2008) reported that the organic matter and especially humic-like substances represent the major part of organic compounds that LL contains. Such organic matter can be classified into three fractions: simple compounds (1) like carbohydrates, organic acids (mainly volatile fatty acids), amino acids and alcohols, which are identifiable by specific analyses, characterized by low molecular weights and are easily biodegradable. Then humic-like substances (2), including humins and humic-like acids which are characteristic on the humification stage and composed of highly aromatic and high molecular weight cellulosic compounds and fulvic-like acids with medium to high molecular weights. This fraction is relatively rich in carboxylic and hydroxylic groups. The last fraction constituting the non humic-like substances (3) corresponds to the dissolved organic carbon that belongs neither to the humic nor to the fulvic-like acids. This fraction is usually called hydrophilic acids and is expected to constitute a substantial part of the dissolved organic carbon. 


\section{CONCLUSIONS}

Considering the geometry of SBRs aeration, it was found that the ratio of aerated volume to anoxic has affected the efficiency of removing organic substances analyzed by $\mathrm{COD}, \mathrm{BOD}_{5}$ and TOC indicators. In the case of the bioreactors operating at the ratio of 0.33 , the removal efficiency was higher compared to those operating at 0.66 . However, in both layouts, these differences were statistically significant. Moreover, it was found that if LL flowing into the reactors has the N/C ratio of 0.1 , the concentration of organic compounds in the outflows was to a greater degree than in the case of the 0.2 ratio.

Regardless of either the N/C ratio or geometry of oxygen supply, there were no statistically significant differences found between the concentrations of bioavailable organics $\left(\mathrm{BOD}_{5}\right)$ and total concentration of organic carbon (TOC) in the outflows.

However, the proportion of dissolved fractions of organic compounds in the outflows seems to be influenced by the SBR geometry and the concentration of $\mathrm{N}$ in LL. Accordingly, It was found that both for TOC and HS, the share of dissolved fraction was lower in the outflows from the SBR actively aerated in 0.33 of volume. Furthermore the $\mathrm{N} / \mathrm{C}$ ratio of 0.1 in raw LL resulting in the highest concentrations of dissolved HS and COD in outflows.

\section{Acknowledgements}

The research was funded by the National Science Center project MINIATURA 2 - Model of adaptation of the biological system to variable ammonium nitrogen load in the process of landfill leachate treatment(DEC2018/02/X/NZ9/00097)

\section{REFERENCES}

1. APHA, AWWA, WEF, 2005. Standard Methods for the Examination of Water and Wastewater, $21^{\text {st }} \mathrm{Ed}$., American Public Health Association, Washington.

2. Berthe C., Redonb E., Feuillade G. 2008. Fractionation of the organic matter contained in leachate resulting from two modes of landfilling: An indicator of waste degradation. Journal of Hazardous Materials, 154, 262-271.

3. Campagna M., Çakmakcı M., Yaman F.B., Özkaya B. 2013. Molecular weight distribution of a full-scale landfill leachate treatment by membrane bioreactor and nanofiltration membrane. Waste Management, 33, 866-870.

4. Chu L., Wang J. 2011. Comparison of polyurethane foam and biodegradable polymer as carriers in moving bed biofilm reactor for treating wastewater with a low $\mathrm{C} / \mathrm{N}$ ratio. Chemosphere, 83, 63-68.

5. Guo W., Ngo H.H., Dharmawan F., Palmer C.G. 2010. Roles of polyurethane foam in aerobic moving and fixed bed bioreactors. Bioresource Technology, 101, 1435-1439.

6. He P.J., Xue J.F., Shao L.M., Li G.J., Lee D.J. 2006. Dissolved organic matter (DOM) in recycled leachate of bioreactor landfill. Water Research, 40, 1465-1473.

7. Huang X., Wei C.H., Yu K.C. 2008. Mechanism of membrane fouling control by suspended carriers in a submerged membrane bioreactor. Journal of Membrane Science, 309, 7-16.

8. Khan S.J., Rehman Z.U., Visvanathan C., Jegatheesan V. 2012. Influence of biofilm carriers on membrane fouling propensity in moving biofilm membrane bioreactor. Bioresource Technology, $113,161-164$.

9. Koc-Jurczyk J., Jurczyk Ł. 2017. Biological Treatment of Landfill Leachate at Elevated Temperature in the Presence of Polyurethane Foam of Various Porosity. Clean - Soil, Air, Water 2016, 44 (9999), $1-8$.

10. Lim J.W., Lim P.E., Seng C.E. 2012. Enhancement of nitrogen removal in moving bed sequencing batch reactor with intermittent aeration during REACT period. Chemical Engineering Journal, 197, 199-203.

11. Lim J.W., Seng C.E., Lim P.E., Ng S.L., Sujari A.N.A. 2011. Nitrogen removal in moving bed sequencing batch reactor using polyurethane foam cubes of various sizes as carrier materials. Bioresource Technology, 102, 9876-9883.

12. Masłon A., Tomaszek J.A. 2015. A study on the use of the BioBall ${ }^{\circledR}$ as a biofilm carrier in a sequencing batch reactor. Bioresource Technology, 196, 577-585.

13. Miao L., Yang G., Tao T., Peng Y. 2019. Recent advances in nitrogen removal from landfill leachate using biological treatments - A review. Journal of Environmental Management, 235, 178-185.

14. Ngo H.H., Guo W., Xing W. 2008. Evaluation of a novel sponge-submerged membrane .bioreactor (SSMBR) for sustainable water reclamation. Bioresource Technology 99, 2429-2435.

15. Ozkaya B. 2005. Chlorophenols in leachates originating from different landfills and aerobic composting plants. Journal of Hazardous Materials, B124, 107-112. 